\title{
Contextual Diversity and Rule-based Adaptive E-learning System Scheme
}

\author{
http://dx.doi.org/10.3991/ijet.v10i5.4799 \\ Kalla Madhu Sudhana \\ Jawaharlal Nehru Technological University, Hyderabad, India
}

\begin{abstract}
-in an adaptive e-learning environment, the system must respond harmoniously to the changes of learner needs. The traditional e-learning systems provide adaptation based on user preferences only. To improve performance, it is required to incorporate learning context information such as the device and network context to determine the appropriate presentation method along with the user preferences. Mainly this paper discussed about the basic categories of context in e-learning environment and proposed an architectural overview of ontology driven rule-based adaptive system for obtaining effective delivery of learning material.
\end{abstract}

Index Terms-Adaptive e-learning system scheme, Categories of context in e-learning domain, Context detection and description mechanism, Ontology-based context model

\section{INTRODUCTION}

The existing learning resources are mainly developed for computer based e-learning. To make the mobile learning useful and successful, there is a need to develop context aware personalized e-learning applications. This issue can be solved through detecting characteristics and constraints of learning device and delivering suitable learning content.

In the context of context aware e-learning, not only the learning device, but also the learning activity of e-learner may be completely different in each moment the learner tries to learn from the corresponding web-based e-learning system.

We have taken the learning context strategies such as learner's device capabilities, learning style and domain specific preferences as the key issues for modeling an integrated context ontological model to support for context aware adaptive e-learning system. So, the system is able to deliver the most suitable learning material based on the learner's specific situation.

The meaning of context-aware as stated by Abowd [1] is: the system considered as "context-aware" if it uses context to provide relevant information to the user based on the user's task. And almost a similar definition given by Cheverst [2] as, a system considered as context-aware if it is able to interpret, extract and use contextual information and adapt its behavior and functionalities to the current context of use.

The advances of mobile communication technologies and rapid adoption of mobile devices with internet capabilities make learners to access the e-learning content "anytime anywhere" with mobile devices [3]. The drastic development in the computational capability of mobile devices has shown the way to take its lead from traditional desktop e-learning systems to mobile based e-learning.
The presentation capabilities of most of the existing learning contents (such as standard documents, image, audio, and video) are restricted to personal computers and they may not be supported by mobile devices [3]. And again, within the mobile devices, there is diversity in their capabilities; hence the context-aware adaptive learning approach needs to provide device-independent e-learning services, through recognizing the various characteristics of the device.

The explosion of learning material in educational domain is leading to information overload and confusion to the e-learner. Adaptation technique considers domain, device and activity details of the e-learner, so that it allows us to deliver précised and customized learning material.

Ontologies and rules provide the most suitable platform for building a highly-responsive and interactive application [4], so mainly this paper concentrates on combining ontology with rule based approach to obtain adaptive functionality. The rule based approach enhances the functional consistency of adaptive delivery process.

\section{ELEMENTS OF CONTEXT}

Context is a multifaceted concept that has been studied in multiple disciplines, each discipline tends to take its own idiosyncratic view that is somewhat different from other disciplines and is more specific than the standard generic dictionary definition. The dictionary definition of context stated as "conditions or circumstances which affect something [5]". In e-learning environment the context is basically concerned about learner and learning environment.

The contextual information describing the learner context is divided roughly into the technical aspects and facets of learning [6]. It is possible to categorize the context in various ways by considering different characteristics of the context. The classified contextual information is useful for context modeling, context management, application development and required to define some specifics of the adaptation process, that helps learner to get highly customized learning content.

In e-learning domain the key components are: Learner, Learning Device and Learning Resources. All the information about the learner situation, concerned to these three basic components referred as the learning context. So, the contextual factors that influence the learner's learning approach considered into three basic categories as:

Device context: In context aware adaptation the device context refers to the presentation of learning resources according to the characteristics of the display device. It is 
TABLE I.

BASIC CATEGORIES OF CONTEXT IN E-LEARNING DOMAIN

\begin{tabular}{|l|l|l|l|}
\hline \multicolumn{1}{|c|}{ Context Category } & \multicolumn{1}{|c|}{ Semantics } & \multicolumn{1}{c|}{ Examples of diversity } & \multicolumn{1}{c|}{ Purpose in Adaptation } \\
\hline Device context & $\begin{array}{l}\text { What type of learning device is } \\
\text { used? }\end{array}$ & $\begin{array}{l}\text { Devices Type: Mobile, Laptop, Smart } \\
\text { phone, etc. } \\
\text { Hardware: Screen size, memory, etc. } \\
\text { Software: supported media Type, mo- } \\
\text { bile browser. }\end{array}$ & $\begin{array}{l}\text { The main mechanism of device content } \\
\text { adaptation is to change the presentation } \\
\text { properties of the content or to select a } \\
\text { suitable version of content as per the device } \\
\text { capabilities before sending to the targeted } \\
\text { device. }\end{array}$ \\
\hline $\begin{array}{l}\text { Domain specific learner } \\
\text { context }\end{array}$ & $\begin{array}{l}\text { What type of learner he is? } \\
\text { What is his preferred area? }\end{array}$ & $\begin{array}{l}\text { Learning Concept: Domain, Topic, } \\
\text { Subject area, etc. } \\
\text { Orientation of learning: such as Appli- } \\
\text { cation, Practical, Theoretical, Examples, } \\
\text { etc. }\end{array}$ & $\begin{array}{l}\text { The domain specific preferences make a } \\
\text { learner to choose a preferred concept and } \\
\text { improves the understanding level of learner. }\end{array}$ \\
\hline $\begin{array}{l}\text { Domain independent } \\
\text { learner context }\end{array}$ & $\begin{array}{l}\text { Who is the learner? } \\
\text { What are the learner prefer- } \\
\text { ences? } \\
\text { What type of content is to } \\
\text { deliver? }\end{array}$ & $\begin{array}{l}\text { Standard, Level of learning, etc. } \\
\text { Media Preferences: Learning time, File } \\
\text { format such as Text, Animation, Au- } \\
\text { dio/video, etc. }\end{array}$ & $\begin{array}{l}\text { Learner personal details and preferences, } \\
\text { identify the learner type and learning style } \\
\text { so as to deliver suitable content. }\end{array}$ \\
\hline
\end{tabular}

the set of device features that supports accessing, processing and presentation of the contents.

Domain specific learner context: The domain specific user characteristics are the preferences of learner concerned with the topic that are conceptually similar to current learning topics such as applications, sub topics, related concepts, prior concepts, etc.

Domain independent learner context: Is concerned with the way in which the learner prefers to learn (such as orientation, media type, etc.). The adaptive user model is based on several kinds of information such as learning style, orientation, etc. [7]. Based on learning style the concerned version of learning concept is delivered to the learner.

The existing literature has covered various diversity problems in these components, such as: different learners may prefer to read different types of learning material (definitions, exercises, case studies, etc.), due to technical and communication advancements there are various types of learning devices (PC, Cell Phone, PDA, etc.) and learning resources are available in different forms and characteristics (reports, books, web sites, videos, interactive files, etc.).

In context aware e-learning applications the conceptual categorization of context in terms of the actors and its diversity is as shown in Table I.

\section{DiVersity In DEVICE CONTEXT}

In web based e-learning applications, to provide suitable content to different client devices, it is required to describe the technical capabilities of the client device (known as the device context).

Different learning devices usually differ in hardware, software, and browsing capabilities. Before adapting learning content to devices, the technical details of learning device are obtained to negotiate between the adaptation system and the learning device. Table II shows the different stages in content adaptation based on device context and concerned device properties which may vary based on device type and model.

In e-learning environment the learning content is in the form of simple webpage or some other format such as a word document, PDF, PPT, etc. (which are compatible for PC based environments). But many mobile devices do not
TABLE II.

DIFFERENT STAGES AND FORMS OF CONTENT ADAPTATION BASED ON A DEVICE CONTEXT

\begin{tabular}{|c|c|c|}
\hline $\begin{array}{c}\text { Stages of } \\
\text { Content } \\
\text { Adaptation }\end{array}$ & $\begin{array}{l}\text { Device Proper- } \\
\text { ties }\end{array}$ & Forms of Content Adaptation \\
\hline \multirow{3}{*}{$\begin{array}{l}\text { Content } \\
\text { presentation }\end{array}$} & Browsers type & \multirow{3}{*}{$\begin{array}{l}\text { Appearance adaptation through } \\
\text { changing content's layout reposition } \\
\text { [8]. } \\
\text { Encapsulation adaptation concerned } \\
\text { with the extraction of the most } \\
\text { important part of the content [9]. }\end{array}$} \\
\hline & Screen sizes & \\
\hline & Accessing mode & \\
\hline \multirow{3}{*}{$\begin{array}{l}\text { Content } \\
\text { processing }\end{array}$} & $\begin{array}{l}\text { Processing } \\
\text { capability }\end{array}$ & \multirow{3}{*}{$\begin{array}{l}\text { Size adaptation by resizing the } \\
\text { dimensions of the media to reduce } \\
\text { its storage size [10]. } \\
\text { Format adaptation by changing the } \\
\text { media format so as to make it suita- } \\
\text { ble for concerned device (e.g. image } \\
\text { format from bitmap to jpeg) [10]. }\end{array}$} \\
\hline & $\begin{array}{l}\text { Storage capabil- } \\
\text { ity }\end{array}$ & \\
\hline & $\begin{array}{l}\text { Supporting } \\
\text { format }\end{array}$ & \\
\hline \multirow{3}{*}{$\begin{array}{l}\text { Content } \\
\text { accesses }\end{array}$} & Protocol & \multirow{3}{*}{$\begin{array}{l}\text { Characteristics adaptation by varying } \\
\text { the content's qualities (such as bits, } \\
\text { color scheme etc.) [11]. }\end{array}$} \\
\hline & Bandwidth & \\
\hline & $\begin{array}{l}\text { HTML,WML, } \\
\text { OS }\end{array}$ & \\
\hline
\end{tabular}

support these wide varieties of file formats that support in the PC based learning. Thus, to deliver the existing learning material to mobile devices (such as cell phones, smart phones, etc.) the solution is twofold: Through a transcoding approach (dynamic conversion of file formats) or maintaining multiple versions of contents that are compatible for various learning devices.

\section{CONTEXT DETECTION AND DESCRIPTION MECHANISM}

Millions of digital educational resources are mainly designed to get access and to deliver through desktop computers, but mobile learning solutions have become an essential part due to mobile technology evolution and that they have become indispensable to modern society. The existing educational resources are not directly accessible by mobile devices as they are not attuned based on the characteristics such as format, size, network-speed, etc. This is an important issue to solve in context aware adaptive e-learning applications. Here, we mentioned the practical approach to get the device profile and learner preference. 


\section{A. Towards Device Context Detection}

To describe the delivery context, there are mainly two standard approaches for detecting the type of device and its technical capabilities: Composite Capabilities/Preferences Profile created by the W3C and User Agent Profile created by the WAP Forum.

CC/PP profile (Composite capabilities/Preferences profile) [12]: CC/PP profile is a description of device capabilities and user preferences and used to guide the adaptation of content presented to the device.

UAProfile (User Agent Profile) [13], 2001): The UAProf specification is based on the CC/PP specification with RDF (Resource Description Framework) as schema and stored in the server called as profile repository. It is an XML file contains the information about the device capabilities and type of user agent. It provides a mechanism for describing the capabilities of client devices to an application server [14].

ScientiaMobile, Inc (http://www.scientiamobile.com/) has focused on this problem and presented an open source XML configuration file called Wireless Universal Resource FiLe (WURFL) (http://wurfl.sourceforge.net), which contains information about the capabilities and features of various mobile devices, typically WAP Devices such as Mobile phone, PDA, smart phone, iPod etc.

WURFL is a Device Description Repository (DDR) in XML format. It defines the characteristics of mobile devices such as markup language, format of images, size of screen, etc., based on matching the user agent string that is identified from the HTTP request object. WURFL is today more popular than pure UAProf or CC/PP solutions [3]. It supports the inheritance of properties from other devices so that they can be categorized according to families and subfamilies.

When client device request a service from a web-server the "HTTP request header field" sent from a client device to a server. Use the "UserAgent" Property from the "HttpRequest Class" to identify the concerned client device model (type) and browser type. But through examining the User Agent header and performing adaptation, will be exclusively based on device/browser identity and not on a particular device capabilities. So the characteristics of the device model can be obtained using the WURFL repository to create the device profile of concerned learner.

\section{B. Obtaining Learner Preference Profile}

The non-technical aspects such as learning style and selection of learning resource services strongly influence the process of learning [6]. The learning context consists of domain-specific information and domain-independent information [15]. The domain specific requirements and learning style of e-learner are the two essential categories of learning context information for assessing the learning resource content.

Here, we are using the static approach for collecting learner context information; where the learner needs to enter the preferred style and orientation of learning. Based on the learner's style-profile an appropriate material will be delivered to learner. The approaches for acquiring the contextual information in our proposed system can be summarized as shown in Table III.
TABLE III.

CONTEXTUAL INFORMATION ACQUISITION APPROACHES

\begin{tabular}{|l|l|}
\hline \multicolumn{1}{|c|}{ Context Type } & \multicolumn{1}{c|}{ Acquisition Approaches } \\
\hline $\begin{array}{l}\text { Device Context } \\
\text { (Static) }\end{array}$ & $\begin{array}{l}\text { Device Context is automatically obtained by means } \\
\text { of using User Agent profile and WURFL Device } \\
\text { Description Repository. }\end{array}$ \\
\hline $\begin{array}{l}\text { Domain specific } \\
\text { learner context } \\
\text { (Dynamic) }\end{array}$ & $\begin{array}{l}\text { The learner can select his preferred domain de- } \\
\text { pendent contents which are conceptually related to } \\
\text { current learning topics such as sub topics, related } \\
\text { topics, etc. from the presentation model using the } \\
\text { user interface. }\end{array}$ \\
\hline $\begin{array}{l}\text { Domain inde- } \\
\text { pendent learner } \\
\text { context (Dy- } \\
\text { namic) }\end{array}$ & $\begin{array}{l}\text { It includes the content format and learning style } \\
\text { entered by learner through filling a form before } \\
\text { starting to learn. The learner can change his prefer- } \\
\text { ences during the time of learning. }\end{array}$ \\
\hline
\end{tabular}

\section{Context Description}

The ontology-based context model uses predefined metadata of the learning contents, learner profile, learner activity, learning device characteristics, etc., for retrieving the context aware personalized learning contents. The learner context model can be formally represented as follows:

Device Context (Device features) and Learner Context (Learner's Preferences) are the two sets of parameters that are considered to obtain context aware adaptive functionality.

Device Context $(\mathrm{DC})=\{\mathrm{dc} 1, \mathrm{dc} 2, \mathrm{dc} 3 \ldots \mathrm{dcn}\}$

Where, dci is one of all features of learner device; $n$ is total number of device features.

Learner Context $(\mathrm{LC})=\{$ Language preference, Content Type preference, Content Format preference\}

Where

Language preference $=$ English, Chinese, etc.

Content Type preference $=$ Example, Application, Case Study, etc.

Content Format preference $=$ Text, Image, Audio, Video, Webpage, etc.

Then the Context Profile is denoted as a 3-tuple: Context Profile $(\mathrm{CP})=<\mathrm{I}, \mathrm{DC}, \mathrm{LC}>$

Where

I: denotes the learner's context identity; DC: denotes the receiving device context; $\mathrm{LC}$ : denotes the learner context

The context aware adaptation mechanism takes two context dimensions DC and LC as arguments and delivers the matching learning resource to learner.

\section{ARchitectural OVERVIEW OF Proposed SYSTEM}

The adaptation mechanism in the proposed adaptive elearning system scheme is mainly based on contextual information that is obtained from various sources. Rulebased systems are simplistic and efficient to implement in knowledge based decision making environments and they are liable for representing the relationships and decision making based on facts. The set of rules and assertions specify how to act. The system examines the conditional statement "IF" and "THEN" to perform the necessary operation. The general form of rule statement is: If $<$ premise $>$ then $<$ consequent $>$. The proposed rule based adaptive system mainly consists of three basic components as shown in Figure 1. 
SHORT PAPER

CONTEXTUAL Diversity AND Rule-BASED ADAPTIVE E-LEARNING SySTEM SCHEME

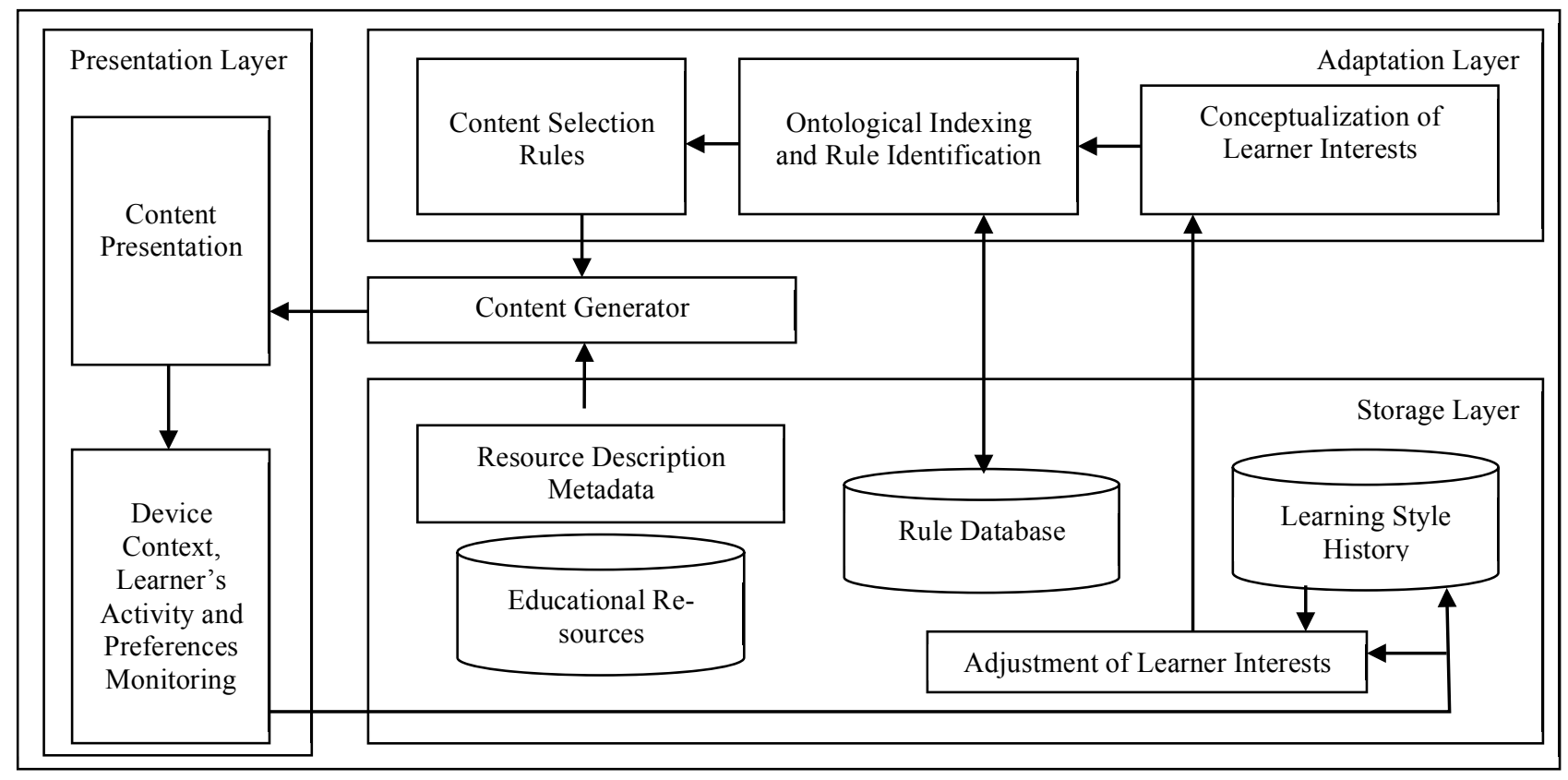

Figure 1. The proposed e-learning system scheme

Presentation layer: Provides an environment to present personalized learning material and conceptual structure of the topics as per the environmental context information, responsible for monitoring and to capture learner's interactions to estimate the behavior of learner.

Adaptation layer: This layer supports context-based adaptive mechanism. The Content Generator delivers appropriate educational resources based on identifying content selection rules influenced by learner's device context and preferences.

Storage layer: It contains three sub-species. The first one, referred to as, Repository of educational resources associated with metadata descriptions. The second one, referred to as, Rule Database, consists of semantic knowledge based rules (nominative rules) that are derived from an ontological learner context model to enhance the efficiency in adaptation process. The third one, referred to as, history database that stores all persistent information about learner's learning style which serves for estimating the learner requirement through comparing the current activity of learner with learning style history.

\section{CONCLUSION}

Most of the current e-learning applications and their learning contents are not suitable for mobile devices due to computational and technical barriers that can impede access to existing online learning resources. In this paper, first we discussed about the basic categories of context and diversity in a device context, and then we addressed the device context and learner context detection and adaptation mechanism so as to deliver suitable content based on contextual information.

We designed the adaptive process to be independent from the presentation and storage layers. The proposed architecture allows separating adaptive rules from the rest of the system, so that the rules can be updated as per the requirements. In the near future, we plan to extend this work to develop ontology based presentation model and implement the proposed system scheme for a course based e-learning environment.

\section{REFERENCES}

[1] Abowd, G. D., Dey, A. K., Brown, P. J., Davies, N., Smith, M., \& Steggles, P, 1999. Towards a better understanding of context and context-awareness. In Handheld and ubiquitous computing (pp. 304-307). Springer Berlin Heidelberg. http://dx.doi.org/10.1007/3540-48157-5 29

[2] Cheverst, Keith and Byun, Hee Eon, 2004. Utilizing Context History to Provide Dynamic Adaptations. Applied Artificial Intelligence, 18 (6). pp. 533-548. http://dx.doi.org/10.1080/0883 9510490462894

[3] Zhao, X., Anma, F., Ninomiya, T., \& Okamoto, T, 2008. Personalized adaptive content system for context-aware mobile learning. International Journal of Computer Science and Network Security, 8(8), 153-161.

[4] Hatala, M., Wakkary, R., Kalantari, L. (2005) "Rules and Ontologies in Support of Real-time Ubiquitous Application". Journal of Web Semantics.

[5] Webster, N., 1980. Webster's new twentieth century dictionary of the English language. Springfield, MA: Merriam-Webster, Inc.

[6] Bomsdorf, B, 2005. Adaptation of Learning Spaces: Supporting Ubiquitous Learning in Higher Distance Education, Dagstuhl Seminar Proceedings 05181 Mobile Computing and Ambient Intelligence: The Challenge of Multimedia.

[7] Paredes, P., \& Rodriguez, P, 2004. A mixed approach to modelling learning styles in adaptive educational hypermedia. Advanced Technology for Learning, 1(4), 210-215. http://dx.doi.org/10.2316/Journal.208.2004.4.208-0823

[8] Yang, S. J., \& Shao, N. W, 2007. Enhancing pervasive Web accessibility with rule-based adaptation strategy. Expert Systems with Applications, 32(4), 1154-1167. http://dx.doi.org/10.1016/ j.eswa.2006.02.008

[9] Yang, S. J., Zhang, J., Chen, R., \& Shao, N. W, 2007. A unit of information-based content adaptation method for improving web content accessibility in the mobile Internet. Electronics and Telecommunications Research Institute (ETRI) Journal, 29(6), 794807.

[10] Chen, L. Q., Xie, X., Ma, W. Y., Zhang, H., \& Zhou, H. Q, 2003, January. Image Adaptation Based on Attention Model for SmallForm-Factor Device. In MMM (p. 421).

[11] Lum, W. Y., \& Lau, F. C, 2003. User-centric content negotiation for effective adaptation service in mobile computing. Software Engineering, IEEE Transactions on, 29(12), 1100-1111.

[12] CC/PP, 2007. Composite Capability/Preference Profiles: Structure and Vocabularies 2.0, W3C Working Draft 30 April 2007. Availa- 


\section{SHORT PAPER}

CONTEXTUAL Diversity AND RulE-BASEd AdAPTIVE E-LEARNING SYSTEM SCHEME

ble at: http://www.w3.org/TR/2007/WD-CCPP-struct-vocab220070430/

[13] UAProf (User Agent Profile)Version 20, 2001: Available at:http://openmobilealliance.org/wp-content/uploads/2012/12/wap248-uaprof-20011020-a.pdf

[14] WAP 2.0, 2002. Wireless Application Protocol Technical White Paper. Available at: http://wapforum.org/what/WAPWhite_Paper1.pdf

[15] Esichaikul, V., Lamnoi, S., \& Bechter, C, 2011. Student Modelling in Adaptive E-Learning Systems. Knowledge Management \& E-Learning: An International Journal (KM\&EL), 3(3), 342-355.

\section{AUTHOR}

Kalla Madhu Sudhana is with the Guru Nanak Institute of Technology (GNIT), which is affiliated to Jawaharlal Nehru Technological University, Hyderabad, India (kallamadhu1@yahoo.com).

Submitted 09 June 2015. Published as resubmitted by the author 30 October 2015. 